\title{
Increasing taxes to reduce smoking prevalence and smoking attributable mortality in Taiwan: results from a tobacco policy simulation model
}

\author{
D T Levy, C P Wen, T Y Chen, M Oblak
}

Tobacco Control 2005;14(Suppl I):i45-i50. doi: 10.1136/tc.2003.005660

See end of article for authors' affiliations

Correspondence to: David T Levy, PhD, 14403 Sylvan Glade Drive, North Potomac, MD 20878, USA; levy@pire.org

\begin{abstract}
Objective: To develop a simulation model to predict the effects of tax policies on smoking prevalence rates and smoking attributable deaths.

Methods: Using data from Taiwan, a simulation model is developed that projects population using birth and death rate data, future smoking rates using initiation, cessation and relapse data, and smoking attributable deaths using smoking prevalence and relative risk estimates. The model projects the number of smokers and smoking related deaths from a baseline year forward. The effects of taxes of different sizes, indexed and unindexed, and temporary versus sustained are modelled using elasticities based on published studies of demand.

Results: The model predicts that sustained tax increases have the potential to substantially reduce the number of smokers and the number of premature deaths, with the effects growing over time. Indexing taxes to inflation stems erosion of the tax effect. In our model, when the tax increases by 10 times (NT\$50) over the recent tax increase (NT\$5) and taxes are indexed to inflation, the smoking prevalence rate falls by over $15 \%$ soon after the tax increase, and by about $30 \%$ in relative terms by the year 2040 , resulting in 4500 lives saved per year.

Conclusions: Tax rises have the ability to substantially affect smoking rates in Taiwan. These effects grow over time and lead to substantial savings in lives and health care costs.
\end{abstract}

A large number of demand studies consistently find that higher cigarette prices are associated with lower cigarette consumption, and that youth are particularly responsive to price increases. ${ }^{12}$ Recent studies distinguishing the effect of price on the number of smokers (participation) from the quantity of cigarettes consumed by continuing smokers find that at least half of the decrease in demand results from reduced prevalence (for example, through increased cessation or lower initiation). ${ }^{3}{ }^{4}$ Since smoking is strongly associated with higher mortality and morbidity, ${ }^{5-7}$ higher taxes can be expected to improve health. These findings have been used to justify tax increases in developed Western countries, such as the USA and UK.

Studies have found that price is at least as an important in less developed nations, including Taiwan, as in the more developed, Westernised nations. ${ }^{8}{ }^{9}$ This paper explores the implications of tax increases for the nation of Taiwan. Taiwan has traditionally had low cigarette prices compared to other nations. Compared to 87 countries, their prices were ranked in the lowest 20-30th percentile. ${ }^{10}{ }^{11}$ Among Western Pacific Region Organizations, cigarette prices in Taiwan were ranked the third lowest of all countries and lowest when taking into account standard of living. ${ }^{10}{ }^{11}$ In 2002, the Taiwan government raised the cigarette tax as part of the Tobacco and Wine Tax Law. The resulting prices, however, still remain low among Asian countries, and further tax increases are being considered.

This paper reports the results of a computer simulation model of tax policies for Taiwan that predicts the effect of the 2002 tax hike and future potential tax hikes on the smoking prevalence of Taiwan. The model is also used to examine how the effects depend on the size of the tax increase and adjustments for inflation. The simulation model is patterned after SimSmoke, a tobacco control policy model developed for the USA. ${ }^{12}{ }^{13}$
The Taiwan model uses price, tax, population, and smoking prevalence data for Taiwan. Because smoking rates of males $(46.7 \%)$ are much larger than that of females $(4.2 \%)$ in Taiwan, ${ }^{14}$ the model projects smoking rates separately for males and females. Using relative risk and smoking prevalence estimates for Taiwan, the model also predicts the effect of tax policies on smoking attributable deaths, so that policymakers can understand the health implications of tax policies in terms of lives saved.

\section{METHODS}

\section{Population and smoking model}

The SimSmoke model, discussed elsewhere, ${ }^{12}{ }^{13}$ projects smoking rates and deaths attributable to smoking. The simulation model begins with the number of smokers, never smokers, and previous smokers by age and sex in the baseline year 2001. The basic model involves a population and a smoking model. A discrete time, first order Markov process is employed to project future population growth and smoking rates over time.

The population growth model incorporates births and deaths. Population and fertility data are obtained from the (census) statistics from the Department of Health, Taiwan, ROC (2001). Mortality data are also from statistics from the Department of Health, Taiwan, ROC (2001), with original data collected by the National Mortality Registration System. Net immigration has been low in recent years, and is not incorporated in the model. Fertility rates have also been low in recent years, but our population estimates are in line with that of other projections (www.stat.gov.tw/bs2/ 2003YearBook.pdf).

Within the smoking model, individuals may evolve from never smokers to smokers through smoking initiation. Individuals are classified as never smokers from birth until they initiate smoking or die. They may evolve through 
cessation from smoker to ex-smoker and may return to smoking through relapse. The rates are specific to age and sex, except for relapse. Relapse depends on age and years since quitting $(1-2,3-5,6-10,11-15,>15$ years).

The source of data on smoking, ex-smoking, never smoking, initiation, and previous year cessation rates is the 2001 Taiwan National Health Interview Survey (NHIS). The NHIS was conducted by the National Health Research Institutes and Bureau of Health Promotion, Taiwan, ROC ${ }^{15}$ to assess various health behaviours including smoking for non-institutionalised citizens in Taiwan. The NHIS uses stratified cluster sampling, with households identified by areas and each person in selected households interviewed. In total, 8458 households were identified and 25464 personal interviews were completed, with a response rate of $93.8 \%$. The survey quality was assured by training interviewers and implementing standardised interview protocols. Because the dataset did not provide reliable data on relapse rates after the first year, we used relapse rates for the USA. $^{5} 61617$

Never smokers are those who have smoked fewer than 100 cigarettes in their lifetime. Of those individuals who have smoked more than 100 cigarettes in their lifetime, smokers are defined as those currently smoking and ex-smokers are defined as those not currently smoking. Due to empirical difficulties in measuring initiation and quitting and to ensure stability of the model, initiation rates at each age are measured as the difference between smoking rate at that age and the previous age. Based on an examination of 2001 prevalence data and cohort data from previous years, ${ }^{15}$ initiation in the model occurs until age 30. Cessation is tracked from age 30. One year cessation rates are defined as those who quit in the last year, with adjustments for relapse based on a recent cessation programme. ${ }^{18}$

Within the smoking model, smoking attributable deaths are predicted using standard attribution measures, based on prevalence rates and the total mortality risks of smokers and ex-smokers relative to non-smokers. ${ }^{19} 20$ Mortality risks are distinguished by age, sex, and smoking types (never, current, and the six ex-smoker groups) based on large scale studies conducted for Taiwan..$^{21} 22$ These estimates are slightly higher, but consistent with earlier results obtained by Liaw and Chen $^{23}$ for Taiwan.

\section{Cigarette prices and taxes}

Based on economic theory, cigarette use in the model is determined by the retail price; smokers consider the price of a good relative to the prices of other goods. The effect of changes in price on smoking rates is related through an equation that depends on the demand elasticity - that is, the percentage change in demand from a $1 \%$ increase in price. Demand may be decomposed into effects on prevalence (that is, the participation elasticity) and quantity smoked (that is, the conditional elasticity). The elasticities used in the model are based on participation elasticities. The model does not track quantity. Since quitting is more likely among those who smoke less, ${ }^{24-26}$ the conditional elasticity is reflected in higher future cessation rates among those who continue smoking at lower quantities.

Since cigarette demand studies generally do not distinguish the effects of price on initiation, cessation, and relapse rates, assumptions were made about the nature of these effects. The effect of price on initiation and cessation rates are determined in the model through the age specific constant price elasticities multiplied by the percentage price change. There is a direct effect on the number of smokers (that is, an immediate additive effect on prevalence) that occurs in the year of a change in the current year price from the previous year price. These are additional multiplicative effects through future cessation rates and initiation rates that occur as long as a price change is maintained. Since initiation and cessation rates are measured for the base year, the effect on these rates depends on the current price relative to that in the base year. The model incorporates no additional effect on relapse rates to avoid double counting - that is, relapse rates are proportionately reduced with reductions in the first year cessation rate.

Using per capita consumption data, Hsieh et a ${ }^{9}$ obtained price elasticities of demand of -0.5 to -0.65 for cigarettes in Taiwan, suggesting that the price elasticity should be greater in Taiwan than in more developed countries $(-0.4)$ but lower than in less developed countries $(-0.8){ }^{8}$ We know of no published studies that distinguish participation elasticities for Taiwan, although studies from China indicate that most of the effect is through participation rather than quantity. ${ }^{27} 28$ Studies from the USA have reported that youth and young adult smoking prevalence rates are more responsive to price than adults. ${ }^{3}{ }^{29}$ Using these studies that distinguish by age with a slight adjustment upward to reflect higher tax elasticities in Taiwan, the simulation model assigns a participation elasticity of -0.6 for those below age 20 years, -0.5 for those ages 20 to $25,-0.4$ for those ages 26 to 35 , and -0.2 for those age 36 years and above. Due to inconsistent results across studies, ${ }^{30}$ the effects of price are not distinguished by sex.

Actual prices and taxes are used for the years 2001 and 2002. Data on retail prices and taxes were obtained from Tsai et al. ${ }^{31}$ They are based on a survey of convenience stores in Taiwan and are consistent with those obtained in Guidon et al. ${ }^{10}$ The retail price was measured by a sales weighted average of local and foreign brands. The simulation model adjusts prices in 2002 to the base year (2001) using a price index.

For the years 2003 forward, an equation relates tax changes to price increases. Some recent evidence indicates that prices in Taiwan increased by twice the amount of the tax. ${ }^{31}$ However, Keeler $e t a l^{32}$ and Sung et a ${ }^{33}$ have found that cigarette prices increased by slightly more than the tax increase, and some of the effects of a tax may be counteracted by smuggling. ${ }^{34}$ Consequently, the simulation model adopts the more conservative approach that price increases by only the amount of the tax change.

To project future prices, the untaxed portion of cigarette prices plus sales tax is assumed to increase with the general price level (that is, with general price inflation). Because excise taxes levied in Taiwan are set in \$NT per pack (20 cigarettes) rather than as a percentage of price, they do not change with the general price level unless a specific policy is implemented to index taxes to prices. Based on data in Tsai et al, ${ }^{34}$ general price inflation is assumed to be $2 \%$ per year in future years.

\section{The method of computation}

The basic model was programmed using Excel software. We separately consider the effect of the tax increase in the year 2002 and the effect of additional tax policies on smoking and death rates from the year 2003 onward. We assume that other (non-tax) policies remain constant at the 2002 levels, which we call the "business as usual" scenario. Unless otherwise indicated, we assume that the tax is maintained at the same level in all future years. We compare predicted smoking rates and death rates to their "business as usual" levels from the year 2003 to 2040.We also estimated cumulative lives saved by summing over each year between 2003 to 2040 (38 years) the difference between the number of deaths at the higher tax and at the 2002 price. 
Table 1 Smoking prevalence rates (\%) predicted under different tax scenarios*

\begin{tabular}{|c|c|c|c|c|c|c|c|c|c|}
\hline & 2001 & 2002 & 2003 & 2005 & 2010 & 2015 & 2020 & 2030 & 2040 \\
\hline \multicolumn{10}{|l|}{ Males } \\
\hline Price at 2001 level of NT\$ $\$ 0.9$ & 47.1 & 47.4 & 46.9 & 46.5 & 44.7 & 42.4 & 40.4 & 36.7 & 34.0 \\
\hline Price change in 2002 to NT $\$ 50.6$ & 47.1 & 44.6 & 44.2 & 43.6 & 41.5 & 38.9 & 36.8 & 32.9 & 30.1 \\
\hline Tax increase of NT $\$ 5$ in $2003 \dagger$ & 47.1 & 44.6 & 43.0 & 42.4 & 40.3 & 37.8 & 35.7 & 31.8 & 29.1 \\
\hline Tax increase of NT\$10 in $2003+$ & 47.1 & 44.6 & 42.0 & 41.4 & 39.3 & 36.8 & 34.7 & 30.9 & 28.3 \\
\hline Tax increase of NT\$25 in $2003 \dagger$ & 47.1 & 44.6 & 39.5 & 39.0 & 36.8 & 34.3 & 32.2 & 28.6 & 26.1 \\
\hline Tax increase of NT $\$ 50$ in $2003 \dagger$ & 47.1 & 44.6 & 36.8 & 36.4 & 34.1 & 31.5 & 29.5 & 25.8 & 23.6 \\
\hline Tax increase of NT $\$ 50$ with inflation adj. $\dagger$ & 47.1 & 44.6 & 36.8 & 36.2 & 33.4 & 30.4 & 28.0 & 23.6 & 20.7 \\
\hline Tax increase of NT $\$ 90$ with inflation adj. & 47.1 & 44.6 & 34.1 & 33.6 & 30.7 & 27.7 & 25.1 & 20.8 & 17.9 \\
\hline \multicolumn{10}{|l|}{ Females } \\
\hline Price at 2001 level of NT $\$ 40.9$ & 4.5 & 4.6 & 4.6 & 4.6 & 4.7 & 4.5 & 4.4 & 4.2 & 3.9 \\
\hline Price change in 2002 to NT $\$ 50.6$ & 4.5 & 4.3 & 4.3 & 4.3 & 4.3 & 4.2 & 4.0 & 3.8 & 3.5 \\
\hline Tax increase of NT $\$ 5$ in $2003+$ & 4.5 & 4.3 & 4.2 & 4.2 & 4.2 & 4.0 & 3.9 & 3.6 & 3.4 \\
\hline Tax increase of NT $\$ 10$ in $2003+$ & 4.5 & 4.3 & 4.1 & 4.1 & 4.1 & 3.9 & 3.8 & 3.5 & 3.3 \\
\hline Tax increase of NT\$25 in $2003+$ & 4.5 & 4.3 & 3.8 & 3.9 & 3.8 & 3.6 & 3.5 & 3.3 & 3.0 \\
\hline Tax increase of NT\$50 in $2003 \uparrow$ & 4.5 & 4.3 & 3.5 & 3.6 & 3.5 & 3.3 & 3.2 & 3.0 & 2.8 \\
\hline Tax increase of NT $\$ 50$ with infl. adj.. & 4.5 & 4.3 & 3.5 & 3.6 & 3.4 & 3.2 & 3.1 & 2.7 & 2.4 \\
\hline Tax increase of NT $\$ 90$ with infl. adj. $t$ & 4.5 & 4.3 & 3.3 & 3.3 & 3.1 & 2.9 & 2.7 & 2.4 & 2.1 \\
\hline
\end{tabular}

\section{RESULTS}

Table 1 contains the results of simulations of tax changes on the smoking prevalence rate, and table 2 contains the results for deaths attributable to smoking. Tobacco use is measured relative to the adult population (above age 17 years). We present the results for males and females separately, due to the large differences in their smoking rates.

We first consider smoking rates in the absence of the price changes in 2002 under the Tobacco and Wine Tax Law-that is, price is maintained at a level of NT\$40.9. With no change in tax policy, smoking rates are predicted to decrease for both males and females. Male rates are predicted to fall from $47.1 \%$ in 2001 to $34.0 \%$ in 2040 . Female rates are predicted to fall by a smaller percentage from $4.5 \%$ in 2001 to $3.9 \%$ in 2040. Deaths attributable to smoking increase over time under this scenario, due both to increases in the population and the aging of cohorts with higher smoking rates. Male deaths increase from about 16600 to 25200 between 2001 and 2040, and female deaths increase from about 1900 to 3900 over the same period.

The Tobacco and Wine Tax Act introduced a new tax scheme on tobacco and wine, and it increased cigarette taxes by NT\$5 per pack. Prices increased from NT\$40.9 to NT\$50.6, almost a $24 \%$ price increase, some of which may be due to factors other than the tax. Assuming that the tax is maintained with no adjustment for inflation, the model predicts that, by the year 2003, male smoking rates fall about $2.7 \%$ in absolute terms or about a $6 \%$ relative drop, with a smaller absolute drop of $0.3 \%$ for females but a similar relative drop. By the year 2040, the model predicts an absolute fall in smoking rates of about $3.9 \%$ for males and $0.4 \%$ for females ( $10 \%$ relative drop). The larger percentage drop for both sexes is because the greater effect on younger smokers spreads slowly over time through the population. Over 1800 lives are saved per year by the year 2040 (1661 males and 226 females). The number of deaths falls more slowly than smoking rates because the health effects of reduced smoking are delayed.

The simulation model was next programmed to simulate the effect of an additional NT\$5 tax per pack above that implemented in 2002. The price is predicted to increase in 2003. At the end of the first year, the effect of the tax increase is to reduce the male smoking rate by $1.2 \%$ from $44.2 \%$ to 43.0\% under the additional NT\$5 2003 tax. By 2040, there is

Table 2 Deaths attributable to smoking predicted under different tax scenarios*

\begin{tabular}{|c|c|c|c|c|c|c|c|c|c|c|}
\hline & 2001 & 2002 & 2003 & 2005 & 2010 & 2015 & 2020 & 2030 & 2040 & Total lives saved $\dagger$ \\
\hline \multicolumn{11}{|l|}{ Males } \\
\hline Price at 2001 level of NT $\$ 40.9$ & 16584 & 16964 & 17349 & 18026 & 18804 & 19455 & 20099 & 23482 & 25160 & - \\
\hline Price change in 2002 to NT\$50.6 & 16586 & 16971 & 17353 & 17972 & 18560 & 19022 & 19348 & 22313 & 23499 & - \\
\hline Tax increase of NT\$5 in $2003 \ddagger$ & 16586 & 16971 & 17357 & 17958 & 18488 & 18893 & 19112 & 21981 & 23055 & 12447 \\
\hline Tax increase of NT\$10 in 2003 & 16586 & 16972 & 17361 & 17944 & 18422 & 18776 & 18899 & 21682 & 22655 & 23662 \\
\hline Tax increase of NT $\$ 25$ in $2003 \ddagger$ & 16586 & 16973 & 17368 & 17910 & 18257 & 18485 & 18373 & 20941 & 21668 & 51431 \\
\hline Tax increase of NT\$50 in 2003 & 16586 & 16975 & 17376 & 17866 & 18056 & 18136 & 17750 & 20064 & 20505 & 84287 \\
\hline Tax increase of NT $\$ 50$ with inflation adj.f & 16586 & 16975 & 17358 & 17813 & 17906 & 17876 & 17362 & 19329 & 19391 & 112926 \\
\hline $\begin{array}{l}\text { Tax increase of NT } \$ 90 \text { with inflation adj.† } \\
\text { Females }\end{array}$ & 16586 & 16976 & 17362 & 17756 & 17671 & 17472 & 16664 & 18328 & 18071 & 150230 \\
\hline Price at 2001 level of NT\$40.9 & 1903 & 1954 & 2005 & 2066 & 2064 & 2260 & 2565 & 3233 & 3934 & - \\
\hline Price change in 2002 to NT\$50.6 & 1903 & 1955 & 2006 & 2061 & 2043 & 2218 & 2488 & 3098 & 3708 & - \\
\hline Tax increase of NT\$5 in $2003 \ddagger$ & 1903 & 1955 & 2006 & 2060 & 2037 & 2206 & 2464 & 3061 & 3648 & 1550 \\
\hline Tax increase of NT\$10 in 2003 $\ddagger$ & 1903 & 1955 & 2007 & 2059 & 2032 & 2195 & 2443 & 3026 & 3594 & 2946 \\
\hline Tax increase of NT $\$ 25$ in $2003 \ddagger$ & 1903 & 1955 & 2008 & 2056 & 2017 & 2167 & 2389 & 2942 & 3461 & 6400 \\
\hline Tax increase of NT $\$ 50$ in $2003 \ddagger$ & 1903 & 1955 & 2009 & 2053 & 2000 & 2133 & 2324 & 2841 & 3304 & 10481 \\
\hline Tax increase of NT $\$ 50$ with inflation adj.‡ & 1903 & 1955 & 2006 & 2047 & 1986 & 2107 & 2282 & 2753 & 3152 & 14200 \\
\hline Tax increase of NT $\$ 90$ with inflation adj. & 1903 & 1955 & 2007 & 2042 & 1966 & 2067 & 2209 & 2636 & 2972 & 18890 \\
\hline
\end{tabular}

*Deaths are per year.

†Total lives saved is calculated from the year 2003-2040 by summing up the difference between the second row and current year.

$\ddagger$ Tax changes are maintained from the year 2003 on. 
an absolute (relative) decrease of $1 \%(3.2 \%)$ for males with similar relative, but smaller absolute changes predicted for females. By 2040, about 500 lives are saved per year by adding a NT\$5 tax to the recent tax. An estimated total of 14000 lives (12500 male and 1500 female) are saved between 2003 and 2040 .

We next considered increases in the tax by NT\$10, NT $\$ 25$, and NT\$50. The smoking rates decrease slightly less than proportionate with the size of the tax. Assuming that the amount of the tax is exactly passed on to consumers (a conservative assumption), a tax of NT\$50 would about double the price from its level in 2002 (NT\$50.6). The model predicts substantial reductions in smoking rates and deaths. Compared to the current 2002 tax, male smoking rates fall 6.5 $\%$, about a $21 \%$ relative reduction. Almost 3000 male lives and 400 female lives are saved per year as a result of the higher tax.

As the general level of prices, including the untaxed portion of cigarette prices, rises, the taxed portion of the price falls relative to the untaxed portion and to other prices, and the price of cigarettes falls relative to the purchasing power of the population. The simulation model was programmed to examine the effect of indexing taxes to inflation. If the NT\$50 tax increase and other excise tax rates are raised with the rate of inflation, there is an additional 3\% absolute reduction and $12 \%$ relative reduction in the male smoking rate by 2040 compared to no indexation. An additional 1250 lives are saved per year by 2040. An estimated total of 127100 lives (112 900 male and 14200 female) are saved between 2003 and 2040 .

A final simulation examined raising the tax so that the price in Taiwan would equal that in Hong Kong (equivalent to NT\$141). To reach that price, a tax of \$NT90 would be imposed. We assume that the tax would be indexed to inflation so that the price stays comparable to that in Hong Kong. The male smoking rate is predicted to drop in absolute terms by $10.1 \%$ by 2003 and by $12.2 \%$ by 2040 compared to the predicted rate under the current tax. As a consequence, approximately 5400 male and 735 female lives would be saved in the year 2040 .

The effect of a tax increase depends on it being maintained. For example, an NT\$50 increase in taxes repealed after one year would only temporarily reduce the number of smokers and would be reversed after the tax was repealed. Minimal deaths would be averted.

We have assumed that the effects of a tax are similar to those in the USA. Based on evidence that taxes may have a larger effect," we also considered how the results of the analysis may be affected by an increase in the elasticity by 0.2 (in absolute terms) for each of the age groups. We found that when an additional tax of NT\$50 is imposed, an additional 770 male lives and 120 female lives are saved per year by the year 2040 (not shown) as compared to the lower elasticities used in the previous analyses.

\section{DISCUSSION}

The simulation model predicts that sustained tax increases have the potential to reduce substantially the number of smokers and the number of premature deaths. The model shows how the effects will depend upon the size of the tax increase. Indexation stems the erosion of tax rate increases and their effects on smoking.

The model shows how the effects of a tax vary over time, since they depend on the past effect of policies, the current ages of purchasers, and the varying smoking rates of different cohorts of smokers. A tax increase affects all age groups in the model, but has the greatest effect in reducing youth smoking prevalence. As a consequence, as youth grow older, the effects of a tax on overall smoking rates build over time.
The health effects of those youth discouraged from smoking by a tax hike are further delayed with premature deaths largely 30-50 years in the future. Similar delays occur with non-tax policies directed at youth initiation, such as youth access to tobacco, ${ }^{13}$ but taxes have additional and more immediate effects through reducing initiation and increasing cessation by those above age 18 .

As suggested by empirical studies, ${ }^{35-37}$ the effects of a permanent price change approximately double over time. For example, a $10 \%$ increase in price leads to about a 3\% drop in prevalence in the first year increasing to about a $6 \%$ drop in prevalence over time. Our long run predictions are consistent with the effects found for Taiwan ${ }^{9}$ and are roughly in between those found for low and high income nations. ${ }^{8}$ Consistent with models of rational addiction, a temporary price change yields minimal effects.

\section{Limitations}

The simulation results depend on the data and structure of the population, smoking, and tax modules. The population and smoking modules employ fairly robust assumptions, and, except for the relapse rates, use data from Taiwan. The model forecasts are relatively insensitive to the relapse rate measures, and conservative measures were used.

Except for changes due to tax policy, the model assumes initiation and cessation rates will remain stable in future years. Increasing levels of income ${ }^{9}$ and increased marketing by international firms with the opening of the market to foreign imports ${ }^{98}$ have been found to increase smoking rates, particularly among young Taiwanese females. ${ }^{38}$ However, the effects of income tend to be smaller for more developed economies, ${ }^{8}$ and recent evidence indicates that higher income and the more educated Taiwanese have lower smoking rates..$^{15}$ Cessation rates may also change with the increasing use of pharmacotherapies and other cessation aids. Thus, it will be important to monitor future initiation and cessation rates.

We used estimates of the relative risk for all causes in Taiwan to project smoking attributable mortality, which may underestimate the true effects. ${ }^{39}$ In particular, relative risks may increase in Taiwan as the quantity smoked and the average duration of smoking (due to earlier smoking initiation in more recent years) increase. ${ }^{14353638}$

A number of assumptions were made in translating tax effects into the model. The effects of price are based primarily on studies of smoking participation, and the model does not explicitly distinguish the role of quantity smoked. We make the conservative assumption that quantity reductions due to taxes lead to an increase in the annual future cessation rate by the same percentage amount as the initial reduction in smoking prevalence.

The simulation model also assumes that the price elasticity is constant over the range of prices. While some recent evidence indicates that large tax hikes have led to large reductions in smoking rates, ${ }^{40}$ most evidence on price effects is generally confined to relatively small price variations. The predictions of the model depend on whether large increases in price will lead to large increases in smuggling. Some of the reductions in smoking can be offset by smokers purchasing cheaper cigarettes. ${ }^{36}{ }^{41}$ The effects of smuggling appear to vary from county to country, ${ }^{42}$ but Tsai $e a^{34}$ found that smuggling is significant in Taiwan. Stricter penalties and/or greater expenditures for enforcement efforts (including improved tracking of cigarette consignments) may reduce the smuggling problem. ${ }^{42}$

The model assumes that future increases in taxes will lead to commensurate increases in the average price of cigarettes. This assumption is conservative in light of prices increasing by twice the amount of a recent tax increase. ${ }^{34}$ The model also 


\section{What this paper adds}

A large body of literature have been used to justify cigarette tax increases as a way to promote health in developed Western countries, such as the USA and UK. Less has been done in middle and low income countries, which might also be expected to benefit from higher prices. This paper presents the results of a computer simulation model that was originally developed for the USA and known as SimSmoke. The data from the USA is replaced by data from Taiwan on population, smoking, and tobacco control policies. The model is used to show that smoking prevalence can be drastically reduced and many lives saved by increasing taxes in Taiwan.

implicitly assumes that the same absolute tax hike is imposed on domestic and international cigarette brands in future years. Due to their lower prices, this implies larger percentage price changes for domestics. For that reason, and because those who consume the lower priced domestics tend to have lower incomes, this would imply larger reductions for the domestics. ${ }^{8}$ However, international brands have been growing in importance since the opening of the Taiwanese market in $1987,{ }^{98}$ and it will be important to track future trends and develop tax policies to counter those trends.

The effect of a tax increase also may depend on the prices of related goods, such as betel quid chewing. In the absence of increased taxes on betel quid and other substitutes, higher taxes on cigarettes could lead to some smokers using these substitute tobacco products. ${ }^{8}$ However, in another paper in this supplement, ${ }^{43}$ we found that betel quid use mostly accompanies smoking, so that an increase in price might actually reduce its use.

Finally, the model assumes that other tobacco control policies stay at their baseline levels. The addition of other policies, such as clean air laws and stricter advertising bans, to an increase in taxes is likely to reduce smoking and death rates further. As other policies are implemented, the effects of the combined policies may be synergistic if norms against smoking become stronger. A separate report ${ }^{44}$ considers how implementing additional policies affect smoking rates and the number of deaths attributable to smoking. Other policies related to the privatisation of domestically produced cigarettes in future years may also affect smoking rates and the effect of taxes on those rates.

The Taiwan SimSmoke model has been developed in such a way that it can be easily modified. We expect that the model will be used to encourage future research on smoking initiation and cessation, relative health risks, and the demand for cigarettes. In particular, it will be important to distinguish the effects of price on smoking participation and quantity, and determine how these effects differ by age and sex. It will also be important to consider how changes in tax translate into changes in price, the effect of smuggling on demand, the substitution between international and domestic brands, the effects of cigarette prices on betel quid use, and the role of other tobacco control policies. As new information on these topics is developed, it will be important to incorporate that information into the model.

\section{Summary}

The model predicts that many lives can be saved by a large increase in taxes. When the tax increases by 10 times (NT\$50) over the recent tax increase (NT\$5) and taxes are indexed to inflation, the smoking rate falls by about $30 \%$ in relative terms and over 4500 lives are saved per year by the year 2040. Besides saving lives, medical costs and productivity losses due to smoking will be reduced. Tax increases are also likely to increase government tax revenues. ${ }^{42}$

\section{Authors' affiliations}

D T Levy, Pacific Institute for Research and Evaluation, University of Baltimore, Baltimore, Maryland, USA

C P Wen, T Y Chen, National Health Research Institute, Taiwan M Oblak, University of Baltimore, Baltimore, Maryland, USA

Competing interests: none declared

\section{REFERENCES}

1 US Department of Health and Human Services. Smoking and health in the Americas: a 1992 report of the Surgeon General in collaboration with the Pan American Health Organization. Atlanta, Georgia: Centers for Disease Control, Office on Smoking and Health, 1992 (DHHS Publication No (CDC) 92-8419.)

2 US Department of Health and Human Services. Preventing tobacco use among young people. A report of the Surgeon General, 1994. Atlanta, Georgia: Public Health Service, Centers for Disease Control and Prevention, Office on Smoking and Health, 1994 (US Government Printing Office Publication No S/N 017-001-00491-0.).

3 Chaloupka F, Grossman M. Price, tobacco control policies and youth smoking. Cambridge, Massachusetts: National Bureau of Economic Research, 1996.

4 Farrelly M, Bray J. Responses to increases in cigarette prices by race/ethnicity, income, and age groups - United States, 1976-1993. MMWR Morb Mortal Wkly Rep 1998;47:605-9.

5 US Department of Health and Human Services. Reducing the health consequences of smoking: 25 years of progress. A report of the Surgeon General, 1989. Rockville, Maryland: Public Health Service, Centers for Disease Control, Office on Smoking and Health, 1989 (DHHS Publication No (CDC) 89-8411.).

6 US Department of Health and Human Services. The health benefits of smoking cessation. A report of the Surgeon General, 1990. Rockville, Maryland: Public Health Service, Centers for Disease Control, Office on Smoking and Health, 1990 (DHHS Publication No (CDC) 90-8416.).

7 US Department of Health and Human Services. Changes in cigarette related disease risk and their implication for prevention and control. Rockville, Maryland: US Department of Health and Human Services, Public Health Service, National Cancer Institute, 1997;305-33 (NIH Publication No.974213.).

8 Chaloupka F, et al. The taxation of tobacco products. In: Jha P, Chaloupka F, eds. Tobacco control in developing countries. New York: Oxford University Press, 2000:237-72.

9 Hsieh C-R, Hu T-W, Lin C-F. The demand for cigarettes in Taiwan: domestic versus imported cigarettes. Contemporary Economic Policy 1999;17:223-34.

10 Guindon GE, Tobin S, Yach D. Trends and affordability of cigarette prices: ample room for tax increases and related health gains. Tobacco Control 2002; 11:35-43.

11 Lal A, Scollo M. Big Mac index of cigarette affordability. Tobacco Control 2002;11:280-2.

12 Levy DT, et al. The use of simulation models for the surveillance, justification and understanding of tobacco control policies. Health Care Manag Sci 2002;5:113-20.

13 Levy DT, Cummings KM, Hyland A. A simulation of the effects of youth initiation policies on overall cigarette use. Am J Public Health 2000;90:1311-4.

14 Wen C-P, Levy DT, Cheng TY, et al. Smoking behaviour in Taiwan, 2001 Tobacco Control 2005; 14(suppl I):i51-5.

15 National Health Research Institutes. National Health Interview Survey (NHIS) in 2001. Bureau of Health Promotion and National Health Research Institutes, 2002. http://nhis.nhri.org.tw.

16 McWhorter WP, Boyd GM, Mattson ME. Predictors of quitting smoking: the NHANES I followup experience. J Clin Epidemiol 1990;43:1399-405.

17 Gilpin EA, Pierce JP, Farkas AJ. Duration of smoking abstinence and success in quitting. J Natl Cancer Inst 1997;89:572-6.

18 Lai C-K. Effectiveness of smoking cessation service in family practice in Taiwan. In: Collection of Research Papers presented at Tobacco or Health in Taiwan. Taipei: Division of Health Policy Research, National Health Research Institutes, 2002

19 Shultz JM, Novotny TE, Rice DP. Quantifying the disease impact of cigarette smoking with SAMMEC II software. Public Health Rep 1991;106:326-33.

20 CDC. Cigarette smoking among adults - United States, 1998. MMWR Morb Mortal Wkly Rep 2000;49:881-4.

21 Wen CP, Tsai SP, Chen CJ et al. The mortality risks of smokers in Taiwan; Part I: cause-specific mortality. Prev Med 2004;39:528-35.

22 Chen C-J, et al. Smoking attributable mortality in Taiwan, 1990-2020. In: Collection of Research Papers presented at Tobacco or Health in Taiwan. Taipei: Division of Health Policy Research, National Health Research Institutes, 2002.

23 Liaw KM, Chen CJ. Mortality attributable to cigarette smoking in Taiwan: a 12-year follow-up study. Tobacco Control 1998;7:141-8.

24 Hughes JR. Reduced smoking: an introduction and review of the evidence. Addiction 2000;95(suppl 1):S3-7. 
25 Hymowitz N, Cummings KM, Hyland A, et al. Predictors of smoking cessation in a cohort of adult smokers followed for five years. Tobacco Control 1997;6(suppl 2):S57-62.

26 Hymowitz N, Sexton M, Ockene J, et al. Baseline factors associated with smoking cessation and relapse. MRFIT research group. Prev Med 1991;20:590-601.

27 Mao ZZ, Hu TW, et al. The demand for cigarettes in China. Chengdu, Sichuan: West China Medical Sciences University, 2000.

28 Mao ZZ. Determinants of the demand for cigarettes, a cross-sectional study. Chinese Health Industry Management 1997:227-9.

29 Lewit EM, Coate D, Grossman M. The effects of government regulation on teenage smoking. Journal of Law and Economics 1981;24:545-69.

30 US DHHS. Women and smoking: a report of the Surgeon General. Rockville, Maryland: Centers for Disease Control and Prevention, National Center for Chronic Disease Prevention and Health Promotion, Office on Smoking and Health, 2001

31 Tsai Y-W. Analysis of cigarette taxation in Taiwan. In: Collection of Research Papers presented at Tobacco or Health in Taiwan. Taipei: Division of Health Policy Research, National Health Research Institutes, 2002.

32 Keeler TE, Hu TW, Barnett PG, et al. Taxation, regulation, and addiction: a demand function for cigarettes based on time-series evidence. J Health Econ 1993:12:1-18.

33 Sung H, Hu T, Keeler T. Cigarette taxation and demand: an empirical model. Contemporary Economic Policy 1994;12:91-100.

34 Tsai YW, Sung HY, Yang CL et al. The behaviour of purchasing smuggled cigarettes in Taiwan. Tobacco Control 2003;12:28-33.
35 Chaloupka FJ. Rational addictive behavior and cigarette smoking. Journal of Political Economy 1991:722-44.

36 Becker GS, Grossman M, Murphy KM. An empirical analysis of cigarette addiction. American Economic Review 1994:396-418.

37 Hu T-W, Mao Z. Effects of cigarette tax on cigarette consumption and the Chinese economy. Tobacco Control 2002;11:105-8.

38 Hsu CC, Levy DT, Wen CP, et al. The effect of the market opening on trends in smoking rates in Taiwan. Health Policy (forthcoming).

39 Wen C-P, Tsai S-P, Chen C-J, et al. The mortality risks of smokers in Taiwan: part I: cause-specific mortality. Prev Med 2004;39:528-35.

40 Sweanor D. The Canadian tobacco tax experience. In: Information Exchange Conference: Non-Smokers Rights Conference, 1994.

41 Baltagi B, Levin D. Estimating dynamic demand for cigarettes using pane data: the effects of bootlegging, taxation and advertising reconsidered. Review of Economics and Statistics 1986;68:148-55.

42 Merriman D, Yurekli A, Chaloupka F. How big is the worldwide cigarette smuggling problem. In: Jha P, Chaloupka F, eds. Tobacco control in developing countries. New York: Oxford University Press, 2000:365-92.

43 Wen CP, Tsai SP, Cheng TY, et al. Uncovering the relation between betel quid chewing and cigarette smoking in Taiwan. Tobacco Control 2005; 14(suppl I):i16-22.

44 Levy D, Wen C-P. The role of public policies in reducing smoking and deaths caused by smoking in Taiwan: Results from the Taiwan Tobacco Policy Simulation Model. Taipei: Division of Health Policy Research, National Health Research Institutes, 2003. 